Professor Willmott's survey follows one made in 1961 by Professor A. W. Merrison, which showed that of physicists with doctorates, 26 per cent entered government service, 22 per cent went into industry, 27 per cent stayed in the universities, and 18 per cent went abroad. After some prodding, Professor Willmott persuaded 26 universities to reply to a similar questionnaire in October 1966, and produced the results shown in Table 1.

\begin{tabular}{|c|c|c|c|c|}
\hline & & & & \\
\hline & First & Ioyment & Present & ployment \\
\hline & No. & Per cent & No. & Per cent \\
\hline Government service & 83 & $11 \cdot 2$ & 79 & $10 \cdot 8$ \\
\hline Industry & 95 & $12 \cdot \overline{9}$ & 79 & $10 \cdot 8$ \\
\hline Universities & 308 & $41 \cdot 8$ & 302 & $41 \cdot 2$ \\
\hline Technical colleges & 18 & $2 \cdot 4$ & 23 & $3 \cdot 1$ \\
\hline Teaching & 18 & $\overline{2} \cdot \overline{4}$ & 16 & $2 \cdot 2$ \\
\hline Abroad & 217 & $29 \cdot 3$ & 234 & $31 \cdot \overline{9}$ \\
\hline Total & 739 & 100 & 733 & 100 \\
\hline
\end{tabular}

The table shows first that a substantial number of physicists have stayed in universities, a piece of conventional wisdom these days, and the fact that government laboratories are now taking fewer than in the past because of the more modest scale of their activities. What alarms Professor Willmott is the sharp increase in the numbers going abroad and the decline in the numbers going into industry. Not only have the numbers declined since 1961, but there is an actual decline between first and present employment, from 12.9 to 10.8 per cent. Professor Willmott fears that physicists take one look at industry and then turn tail and rush back to the universities as fast as they can. (It is fair to point out that the Swann report did not paint such a dismal picture-it suggested that the proportion going into industry was nearer 20 per cent.)

These figures are not, perhaps, surprising, but add to the volume of evidence which is now accumulating about the use of qualified manpower in Britain. But Professor Willmott has gone further in seeing differences between different branches of physics. While the sample was smaller, and the division between different branches of the subject sometimes blurred, the figures are revealing. Of solid state physicists, for example, 19.7 per cent take their first job in industry, while only 5.7 per cent of nuclear and elementary particle physicists do so, and only $2 \cdot 6$ per cent of theoretical physicists. In each case the numbers show a decline between first and present employment. The numbers staying in universities- 36.7 per cent of the solid state physicists, 41 per cent of the particle physicists, and $55 \cdot 3$ per cent of the theorists-are almost constant between first and present employment. It is difficult to draw any conclusions from this, except the obvious one that investment in solid state research in universities is more effective industrially than investment in other forms of physics; it is still a poor investment, though.

\section{In and Out of Space}

THIs is likely to have been a week of great importance for space research in Europe. Although Europa I, the sixth in the programme of rocket launchings being organized by ELDO from Woomera in Australia, failed to leave the ground on Monday, July 10, the chances are brighter than they have been for at least a year that there will now be some sensible marriage of the collaborative programmes in Europe for rocket development and space research. Certainly the proposal that ELDO (European Launcher Development Organization) and ESRO (European Space Research Organization) should be merged was one of those discussed at a meeting of government delegates at Rome this week. It remains to be seen whether member nations will be prepared to sink their separate ambitions in a programme which would develop a launching vehicle and then provide something for it to do. Another of the questions to be decided is how best to provide machinery for a continuing review of policies within ELDO and ESRO, married or single. Nobody wants to repeat the unseemly public squabbles which nearly brought ELDO to an end a year ago.

European space research will also be helped along a little bit by the holding in London between July 17 and 29 of the annual ICSU meetings of the IQSY (International Year of the Quiet Sun) and of COSPAR. It is thought that the IQSY meeting will be one of the first opportunities to survey the work of that period of collaborative activity.

\section{Good Health}

There has been a curious contrast in the past week between the annual report of the Ministry of Health (HMSO, 19s.), with its cosy account of how the National Health Service in Britain is developing, and some of the things which doctors have been saying at the annual conference of the British Medical Association at Bristol. Innocent observers would be hard pressed to know whether the service is making progress towards some comfortable millennium or, alternatively, will have collapsed before the year is out.

The Ministry of Health acknowledges that the National Health Service "continued to be the subject of much public discussion", and regrets that "some of this has sought to give the impression that the year has been one of disappointment and failure". The truth, says the ministry, is that there has been "a striking measure of success". In practice, $£ 75$ million is to be spent on hospitals in the current financial year, which is said to be 63 per cent more than the rate of spending (in real terms) before the war; but in any case the ministry plans to spend $£ 100$ million a year in the next decade on new hospital building. The report unfortunately does not say whether the ministry considers an increase of 63 per cent in the rate of hospital renewals is enough to cover the increased sophistication of hospital treatment since before the war.

On the productivity of hospitals, the ministry points out that the number of patients being treated in hospitals has increased by 30 per cent in the past decade even though the population as a whole has only increased by $7 \cdot 6$ per cent. There are also increases in the numbers of patients treated in each available hospital bed-in 1956 the average was $16 \cdot 6$ patients per bed per year and in 1966 it had increased to $22 \cdot 6$. The ministry is also able to claim that medical staffs in hospitals have increased numerically by 60 per cent since 1949, but the report admits that still more doctors are necessary if the hospitals are to function efficiently. It points out that, in the past two or three years, there has been a vigorous growth of health and welfare services provided by local authorities. One 